\title{
Probiotic therapy in patients with irritable bowel syndrome: does it have a real role?
}

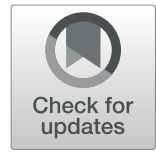

Iman Mohamed Fawzy ${ }^{1}$ Eman Mohamed ElGindy ${ }^{1}$, Omar Abdel-Samie ${ }^{2}$ and Heba Aly ${ }^{1 *}$ (D)

\begin{abstract}
Background: Irritable bowel syndrome (IBS) is one of the most prevalent functional gastrointestinal disorders (FGIDs). There is good evidence that microbiota plays a predominant role in the IBS pathophysiology. The aim of the study is to evaluate the role of probiotics in improvement of IBS symptoms via IBS-symptom severity scale (IBSSSS Arabic version) and improvement of quality of life via irritable bowel syndrome-quality of life survey (IBS-QOL).

Results: This double-armed comparative trial was conducted on IBS patients, who fulfill ROME IV criteria and the IBS diagnostic questionnaire between August and December 2019. Ninety patients were followed up for 4 weeks from the first visit. The first group was prescribed probiotics (10 billion colony of Lactobacillus delbruekii and Lactobacillus fermentum) and itopride hcl $50 \mathrm{mg}$ three times daily, while the second group received only itopride hcl $50 \mathrm{mg}$ by the same dose for 4 weeks. There was a highly significant improvement in the IBS-SSS score in group 1 after 4 weeks of treatment than in group $2(137.56 \pm 67.53$ vs $258.44 \pm 34.18)(p=0.001)$. Also, there was a highly significant improvement in the overall QOL terms in group 1 in comparison with baseline QOL score [with overall mean score $(60.64 \pm 7.77)$ at baseline vs $(81.54 \pm 7.87)$ at 4 weeks ( $p$ value $<0.001)$ ].
\end{abstract}

Conclusion: Probiotics are useful for the improvement of IBS symptoms and quality of life of the studied patients. Larger multicenter studies are needed in the future.

Keywords: Irritable bowel syndrome, Intestinal microbiota, Probiotics, Quality of life, Rome VI criteria

\section{Background}

IBS is a functional bowel disorder and one of the most commonly diagnosed gastrointestinal illnesses. It is a symptom-based condition characterized by abdominal pain or discomfort, with altered bowel habits, in the absence of any other disease to cause these sorts of symptoms, IBS negatively affects quality of life and may result in missed school or work [1].

The Rome classification system was introduced by an international group of gastrointestinal experts at the University of Rome, Italy, and is used in daily practice for patients with gastrointestinal complaints [2]. The Rome IV criteria were introduced in May 2016 and are currently used to diagnose IBS by healthcare providers in daily practice. It has been classified into four main

\footnotetext{
*Correspondence: drhebaismail105@gmail.com

${ }^{1}$ Tropical Medicine Department, Ain Shams University Hospitals, Cairo, Egypt Full list of author information is available at the end of the article
}

types depending on whether diarrhea is predominant, constipation is predominant, both are present, or we cannot classify (IBS-diarrhea, IBS-constipation, IBS-M, and IBS-unclassified) respectively [3].

There is strong evidence supporting the role of bacterial, viral, and parasitic infections in triggering IBS [4]. Some IBS patients respond well to certain non-absorbable antibiotics and prebiotic/probiotic administration [5]. Some of them show improvement after fecal transplantation. Therefore, the role of the intestinal microbiota emerges as an essential feature in developing future therapeutic approaches in IBS [6].

A growing body of evidence indicates dysbiosis as a hallmark of IBS. Despite divergences between studies, there is good evidence that the microbiota is a predominant factor in the IBS pathophysiology [7].

Under normal circumstances, mucus epithelium barrier confines microbes to the epithelial surface or intestinal 
lumen where homeostatic immune responses are induced to maintain barrier integrity and tolerance among commensal microbes. This enables microbes to persistently colonize the intestine and perform symbiotic functions. However, once the barrier is breached by influx of inflammatory mediators, pathogens or any agents that provoke intense immune reactions, severe inflammation occurs and this will affect the intestinal environment, and changes the gut microbiota composition [8]. Briefly, alteration in gut microbiota could contribute to IBS pathogenesis by altering gut immunity and integrity, and modulation of gut neuromuscular junction and gut-brain axis [9].

The aim of the current study is to evaluate the role of probiotics in improvement of IBS symptoms via irritable bowel syndrome-symptom severity scale (IBS-SSS) (Arabic version licensed by Rome Foundation), also the improvement of quality of life via irritable bowel syndrome-quality of life survey (IBS-QOL).

\section{Methods}

This double-armed clinical trial was conducted on 90 IBS patients, who fulfill ROME IV criteria and the IBS diagnostic questionnaire (Arabic version licensed by Rome Foundation) between August 2019 and December 2019. Data of the patient, with suspected IBS during the study period, were reviewed and the patients who fulfilled the inclusion criteria were enrolled into this study. A written consent was obtained from all included patients. The patients who agreed to participate were then randomly assigned into two equal groups and were followed up after 4 weeks from the first visit.

Any patient with red flags (e.g., weight or appetite loss, iron deficiency anemia, fever, or rectal bleeding), known inflammatory bowel disease or celiac disease patients, patients above 50 years of age, uncontrolled long standing (> 5 years) diabetics, and immuno-compromised patients were excluded from the study.

The included patients aged from 18 to 50 years fulfilling Rome IV criteria for diagnosis of IBS: Recurrent abdominal pain (on average, at least 1 day/week in the last 3 months) associated with two or more of the following: related to defecation, associated with a change in frequency of stool, associated with a change in form of stool. Patients should fulfill Rome Foundation IBSdiagnostic questionnaire.

All patients were subjected to initial evaluation by full history taking, questionnaires for (IBS diagnostic questionnaire, IBS-SSS, and QOL-IBS survey), clinical examination, investigations (including $\mathrm{CBC}$, ESR, CRP, random sugar, HbA1c, thyroid profile, and stool analysis), and radiological assessment by pelvi-abdominal ultrasound to exclude any organic cause. Group one (45 patients) was prescribed probiotic (Lactobacillus delbruekii and $L$. fermentum) 10 billion colony forming units and itopride $50 \mathrm{mg}$ three times daily for 4 weeks while group two (45 patients) was prescribed only itopride $50 \mathrm{mg}$ three times daily for 4 weeks. Then, reassessment of the questionnaires was done after 4 weeks of treatment for comparison.

\section{Statistical analysis}

Analysis of data was done using SPSS program version 23. Quantitative data were presented as mean and SD. Qualitative data were presented as count and percentage. Student $t$ test was used to compare quantitative data between two study groups and chi-square test was used for comparison of qualitative data. Paired sample $t$ test and repeated measure ANOVA test were used for comparison of quantitative data at different time points for the same group. $P$ value $<0.05$ was considered statistically significant.

\section{Results}

The mean age for the patients included in the study was $34.61 \pm 8.23$. Considering the gender, patients were almost equal with 44 males (48.9\%) vs 46 females (51.1\%). In relation to residence, the majority of patients (96.7\%) were coming from urban areas. Regarding the medical history of the patients included in the study where only 8 patients $(8.9 \%)$ were controlled diabetics, and 17 patients (18.9) were hypertensive. About smoking, 24 patients $(26.7 \%)$ were smokers, non-of them $(0.0 \%)$ were alcoholic or drug abuser.

Table 1 shows the classification according to ROME IV criteria of the patients included in the study according to the type of IBS. Thirty-two patients (35.6\%) included in the study suffer from constipation type IBS, 24 patients $(26.7 \%)$ suffer from diarrhea type while $34 \mathrm{pa}$ tients $(37.8 \%)$ suffer from mixed type.

Although there was a highly significant improvement in the severity of symptoms in both groups when compared to their baseline, but group 1 showed a highly significant improvement when compared with group $2(p=$ 0.001) (Table 2; Fig. 1).

Figure 2 showed that for IBSS score, there was significant effect indicating significant change in score over time. The baseline score was statistically significant indicating that the mean score differed significantly between the study groups. There is an interaction between time and group variables.

Table 1 Type of IBS in all patients included in the study

\begin{tabular}{llll}
\hline & & N & $\%$ \\
\hline Type of IBS & Constipation & 32 & $35.6 \%$ \\
& Diarrhea & 24 & $26.7 \%$ \\
& Mixed & 34 & $37.8 \%$ \\
\hline
\end{tabular}


Table 2 IBS-SSS before and after treatment

\begin{tabular}{|c|c|c|c|c|c|c|}
\hline & Min. & Max. & Mean & SD & $\mathrm{F}^{\mathrm{a}}$ & $P$ value \\
\hline Baseline IBSS score in group 1 & 210.00 & 400.00 & 315.56 & 41.65 & 241.61 & $<0.001$ \\
\hline IBSS score after 4 weeks in group 1 & 0.00 & 290.00 & 137.56 & 67.53 & & \\
\hline Baseline IBSS score in group 2 & 250.00 & 330.00 & 292.76 & 21.30 & 49.77 & $<0.001$ \\
\hline \multirow[t]{3}{*}{ IBSS score after 4 weeks in group 2} & 180.00 & 330.00 & 258.44 & 34.18 & & \\
\hline & \multicolumn{2}{|c|}{ Group $1(n=45)$} & \multicolumn{2}{|c|}{ Group $2(n=45)$} & & \\
\hline & Mean & SD & Mean & SD & 10.72 & $<0.001$ \\
\hline IBSS score after 4 weeks & 137.56 & 67.53 & 258.44 & 34.18 & & \\
\hline
\end{tabular}

Repeated measure ANOVA test (Bonferroni post hoc test showed significant difference between each two time points)

There was a highly significant improvement in the IBS-SSS in group 1 after 4 weeks of treatment than in group $2(137.56 \pm 67.53$ vs $258.44 \pm 34.18)(\mathrm{p}=0.001)$. Also, there was a highly significant improvement in the overall QOL terms (dysphoria, interaction with activity, body image, health worry, food avoidance, social reaction, sexual activity, and relationship scores) in group 1 in comparison with baseline OQL score [with overall mean score $(60.64 \pm 7.77)$ at baseline vs $(81.54 \pm 7.87)$ at 4 weeks ( $p$ value $<0.001)$ ] (Table 3$)$.

For group 2, there were highly significant improvement in some terms (dysphoria, interference with activity, body image, and health worry scores) while other terms (food avoidance, social reaction, sexual activity, and relationship) showed no significant changes, the
OQL score showed no significance too ( $p$ value 0.18 ) (Table 4).

When comparing the two groups, a high significant difference was found regarding the overall QOL at 4 weeks ( $p$ value $<0.001$ ) but there was no significant difference between them regarding body image ( $\mathrm{p}$ value 0.16 ), food avoidance ( $p$ value 0.95$)$, and sexual scores ( $p$ value 0.14) (Table 5).

Figure 3 showed that for overall QOL score, there was significant effect indicated by the significant change in score over time between the 2 groups. There was no statistical significance between the 2 groups at baseline as indicated by the mean score what did not differ significantly between the study groups. There is an interaction between time and group variables.

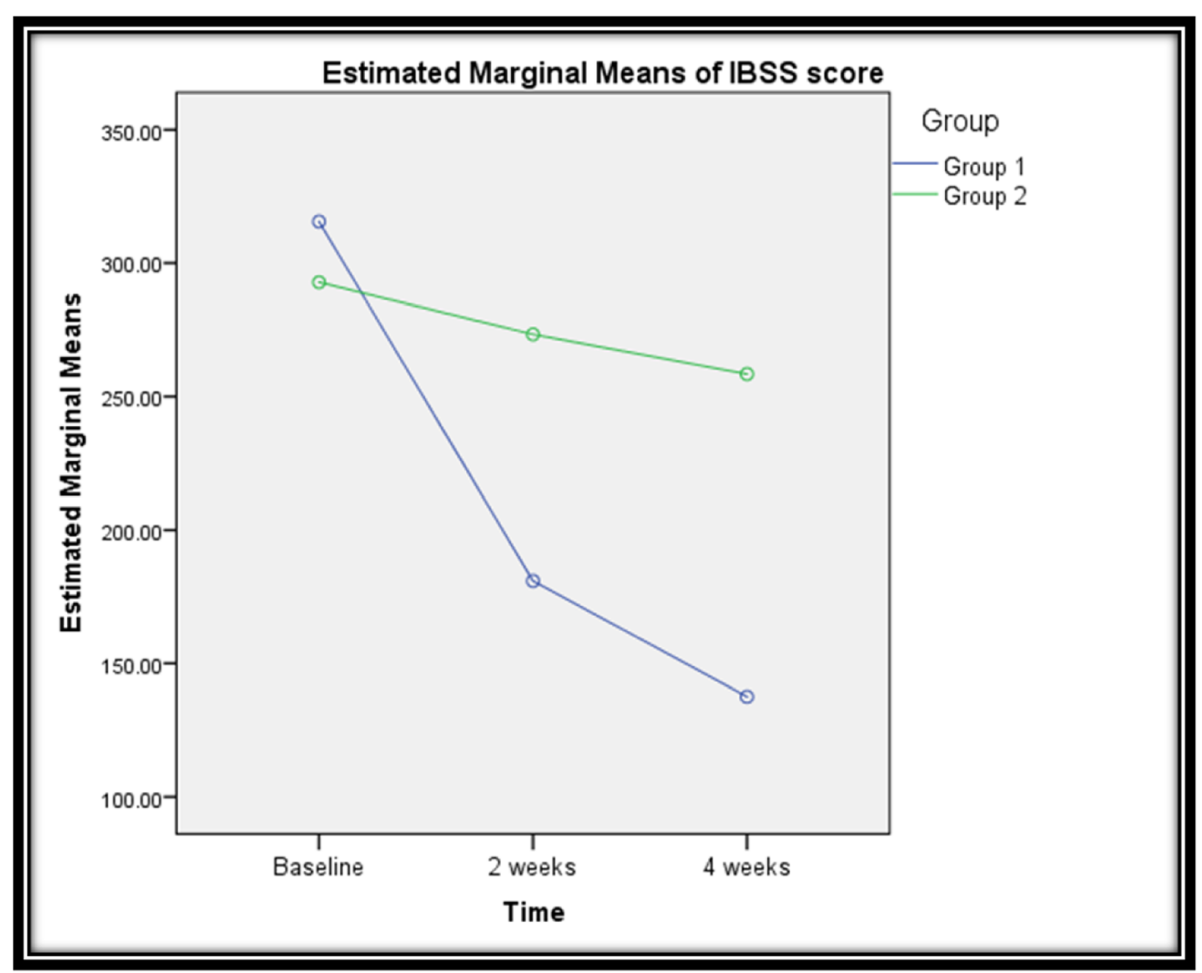

Fig. 1 Comparison between 2 groups regarding IBSS score after 4 weeks 


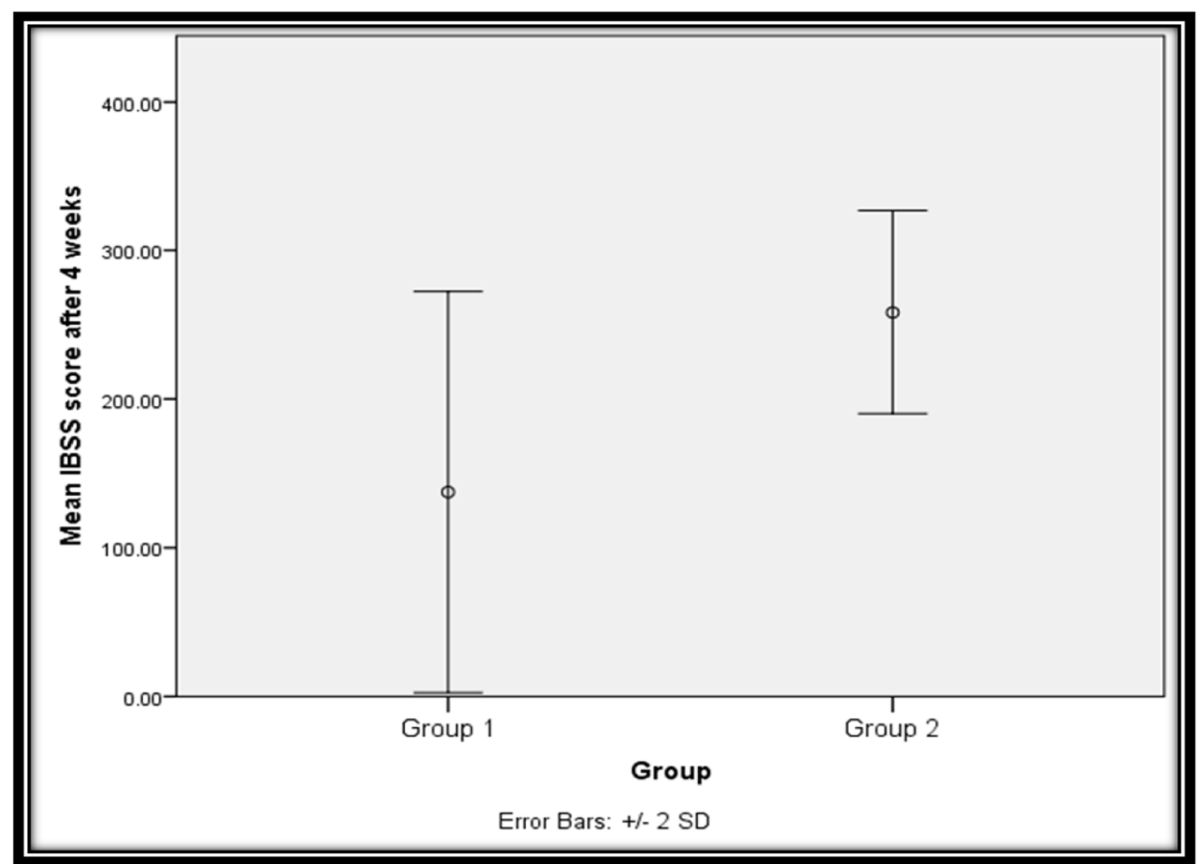

Fig. 2 Comparison between two groups regarding change in IBSS score overtime

Table 3 QOL scores before and after treatment (group 1) ${ }^{\mathbf{a}}$

\begin{tabular}{|c|c|c|c|c|c|}
\hline & Min. & Max. & Mean & SD & $P$ value \\
\hline Baseline dysphoria score & 25.00 & 65.63 & 51.18 & 9.64 & $<0.001$ \\
\hline 4 weeks dysphoria score & 46.88 & 96.88 & 79.17 & 10.68 & \\
\hline Baseline interference with activity score & 35.71 & 75.00 & 58.65 & 9.18 & $<0.001$ \\
\hline 4 weeks interference with activity score & 53.57 & 100.00 & 79.76 & 7.65 & \\
\hline Baseline body image score & 43.75 & 193.75 & 71.39 & 20.58 & $<0.001$ \\
\hline 4 weeks body image score & 56.25 & 100.00 & 89.44 & 10.13 & \\
\hline Baseline health worry score & 33.33 & 91.67 & 62.22 & 13.72 & $<0.001$ \\
\hline 4 weeks health worry score & 50.00 & 100.00 & 81.48 & 11.22 & \\
\hline Baseline food avoidance score & 16.67 & 66.67 & 43.15 & 10.10 & $<0.001$ \\
\hline 4 weeks food avoidance score & 25.00 & 91.67 & 69.81 & 12.47 & \\
\hline Baseline social reaction score & 12.50 & 87.50 & 64.72 & 13.47 & $<0.001$ \\
\hline 4 weeks social reaction score & 56.25 & 100.00 & 84.03 & 9.93 & \\
\hline Baseline sexual score & 62.50 & 100.00 & 88.89 & 12.84 & $<0.001$ \\
\hline 4 weeks sexual score & 62.50 & 100.00 & 93.33 & 10.53 & \\
\hline Baseline relationship score & 41.67 & 91.67 & 67.78 & 11.18 & $<0.001$ \\
\hline 4 weeks relationship score & 50.00 & 100.00 & 82.04 & 9.39 & \\
\hline Baseline overall QOL score & 33.09 & 74.26 & 60.64 & 7.77 & $<0.001$ \\
\hline 4 weeks overall QOL score & 50.00 & 94.12 & 81.54 & 7.87 & \\
\hline
\end{tabular}

${ }^{\text {aPaired samples } t \text { test }}$ 
Table $4 \mathrm{QOL}$ score before and after treatment (group 2) ${ }^{\mathrm{a}}$

\begin{tabular}{|c|c|c|c|c|c|}
\hline & Min. & Max. & Mean & SD & $P$ value \\
\hline Baseline dysphoria score & 25.00 & 68.75 & 51.94 & 11.11 & 0.03 \\
\hline 4 weeks dysphoria score & 25.00 & 81.25 & 50.28 & 11.90 & \\
\hline Baseline interference with activity score & 32.14 & 85.71 & 64.60 & 8.78 & 0.01 \\
\hline 4 weeks interference with activity score & 32.14 & 78.57 & 66.43 & 9.91 & \\
\hline Baseline body image score & 62.50 & 93.75 & 79.31 & 8.30 & $<0.001$ \\
\hline 4 weeks body image score & 68.75 & 100.00 & 86.94 & 5.93 & \\
\hline Baseline health worry score & 58.33 & 91.67 & 78.15 & 9.45 & 0.004 \\
\hline 4 weeks health worry score & 50.00 & 100.00 & 75.00 & 12.05 & \\
\hline Baseline food avoidance score & 41.67 & 91.67 & 70.00 & 12.86 & 0.62 \\
\hline 4 weeks food avoidance score & 41.67 & 91.67 & 69.63 & 12.83 & \\
\hline Baseline social reaction score & 62.50 & 93.75 & 77.22 & 8.85 & 0.17 \\
\hline 4 weeks social reaction score & 56.25 & 93.75 & 76.53 & 9.44 & \\
\hline Baseline sexual score & 75.00 & 100.00 & 96.11 & 8.77 & 0.32 \\
\hline 4 weeks sexual score & 75.00 & 100.00 & 96.39 & 8.69 & \\
\hline Baseline relationship score & 41.67 & 100.00 & 73.33 & 13.37 & 0.29 \\
\hline 4 weeks relationship score & 41.67 & 100.00 & 74.07 & 13.20 & \\
\hline Baseline overall QOL score & 50.74 & 80.88 & 69.13 & 6.34 & 0.18 \\
\hline 4 weeks overall QOL score & 50.74 & 84.56 & 69.71 & 7.23 & \\
\hline
\end{tabular}

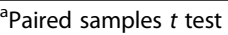

\section{Discussion}

IBS is one of the most prevalent functional gastrointestinal disorders (FGIDs), affecting around $11 \%$ of the adult population worldwide. Due to the lack of specific and sensitive diagnostic biomarkers, IBS is still diagnosed by symptomatic criteria, namely, the Rome criteria (Rome IV in its current version) [10]. The Rome classification system was introduced by an international group of gastrointestinal experts at the University of Rome, in May 2016 Italy, and is used in daily practice for patients with gastrointestinal complaints [3].

Table 5 Comparison between the 2 groups regarding $\mathrm{QOL}^{\mathrm{a}}$

\begin{tabular}{|c|c|c|c|c|c|}
\hline & \multicolumn{2}{|c|}{$\begin{array}{l}\text { Group } 1 \\
(N=45)\end{array}$} & \multicolumn{2}{|c|}{$\begin{array}{l}\text { Group } 2 \\
(N=45)\end{array}$} & \multirow[t]{2}{*}{$\begin{array}{l}P \\
\text { value }\end{array}$} \\
\hline & Mean & SD & Mean & SD & \\
\hline Dysphoria score & 79.17 & 10.68 & 50.28 & 11.90 & $<0.001$ \\
\hline Interference with activity score & 79.76 & 7.65 & 66.43 & 9.91 & $<0.001$ \\
\hline Body image score & 89.44 & 10.13 & 86.94 & 5.93 & 0.16 \\
\hline Health worry score & 81.48 & 11.22 & 75.00 & 12.05 & 0.01 \\
\hline Food avoidance score & 69.81 & 12.47 & 69.63 & 12.83 & 0.95 \\
\hline Social reaction score & 84.03 & 9.93 & 76.53 & 9.44 & $<0.001$ \\
\hline Sexual score & 93.33 & 10.53 & 96.39 & 8.69 & 0.14 \\
\hline Relationship score & 82.04 & 9.39 & 74.07 & 13.20 & 0.001 \\
\hline Overall QOL score & 81.54 & 7.87 & 69.71 & 7.23 & $<0.001$ \\
\hline
\end{tabular}

${ }^{\mathrm{a} S t u d e n t} t$ test
Probiotics may influence the IBS symptoms including abdominal pain, bloating, distension, flatulence, and altered bowel movements [11]. In 2015, a large meta-analysis of 24 human clinical trials concluded that probiotics, overall, were more beneficial than placebo in reducing abdominal pain and symptom severity scores [12].

The mean age of the patients included in this study was $(34.61 \pm 8.23)$ with 44 males $(48.9 \%)$ versus 46 females (51.1\%), which is not consistent with [13] who stated that IBS has a higher prevalence in women than men; however, other studies such as [14, 15] did not report any significant difference between gender.

These results may be caused by the various differences between Asian and Western patients with IBS, including a hygiene hypothesis model, differences in intestinal microbiota and diet, or cultural differences in healthcareseeking behavior [16].

In relation to residence, the majority of patients (96.7\%) were coming from urban areas. This finding agreed with that by [17] who stated that most of their patients also were coming from urban areas (rural 4\%, urban 96\%). According to Rahman et al., urban lifestyle is reported to be associated with greater psychological stress, and thus may be associated with a higher prevalence of IBS compared to rural living [18].

The results of the Rome IV diagnostic questionnaire for our patients revealed that in the recurrent abdominal pain the minimum score was 3 and the maximum score 


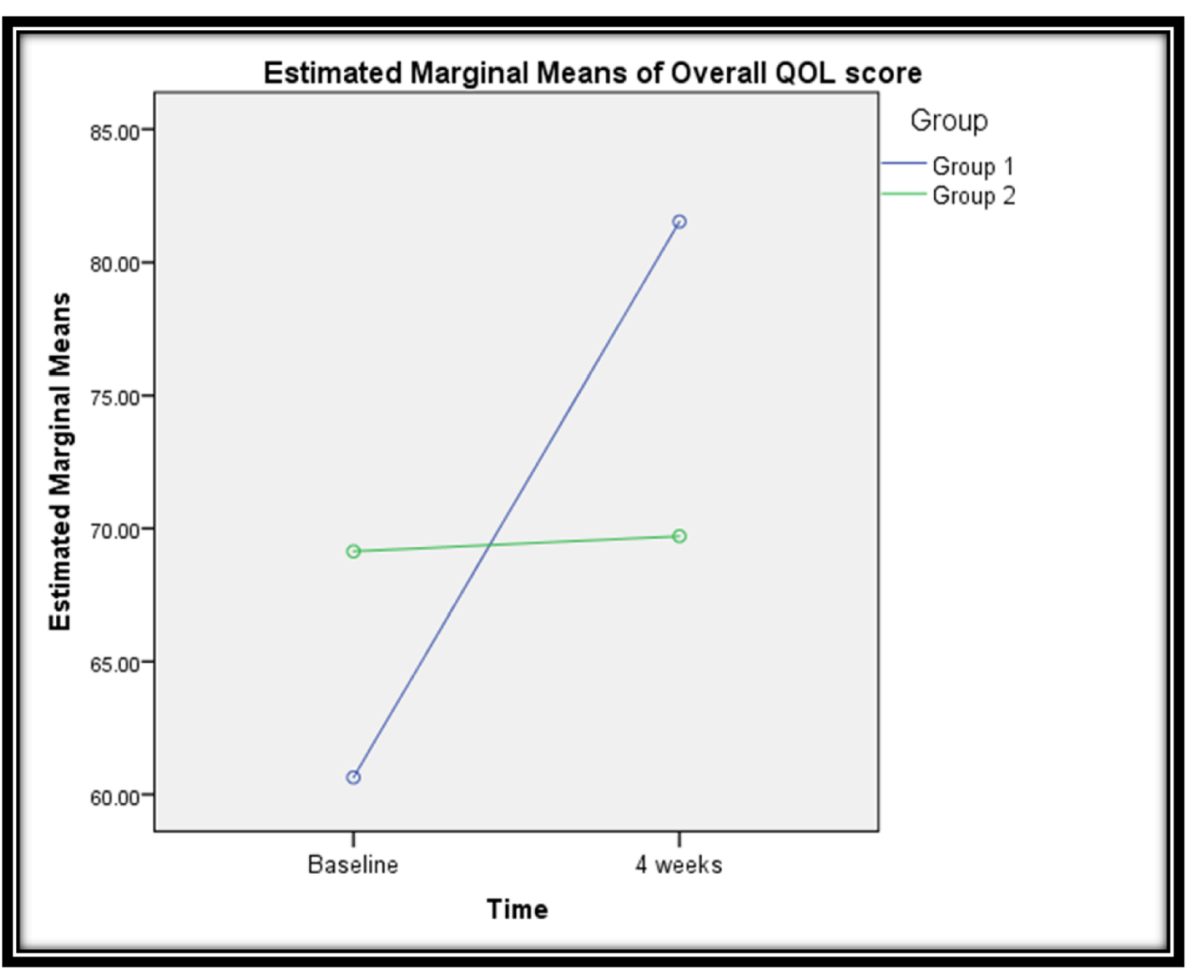

Fig. 3 Comparison between two groups regarding change in overall QOL score overtime

was 7 (5.46 \pm 0.74$)$; pain related to defecation, the minimum score was 5 while maximum score was 9 (6.82 \pm 0.94); pain associated with change in frequency of stool, the minimum score was 5 vs maximum score of 10 $(6.86 \pm 1.02)$; pain associated with the form of stool, the minimum score was 4 while the maximum score was 10 $(6.30 \pm 1.22)$; symptom onset at least 6 months prior to diagnosis, the minimum and the maximum scores were the same $1(1.00 \pm 0.00)$; and regarding the form of stool, the minimum score was 1 and the maximum was 3 (2.02 \pm 0.86$)$.

According to Palsson et al., sensitivity of ROME IV IBS-diagnostic questionnaire was $62.7 \%$ for IBS and specificity was $97.1 \%$ [19].

Assessment of severity of symptoms was done using IBS-SSS questionnaire at the baseline visit and after 4 weeks of treatment. This is the most frequently used measure for evaluating IBS severity. Items relate to pain, bowel dysfunction, and overall well-being. It is commonly used as an outcome measure in clinical trials because it is highly responsive to change with treatment [20].

In the current study, both groups showed an improvement in the IBS-SSS after 4 weeks of treatment but when comparing group 1 with group 2, there was highly significant improvement in the IBS-SSS score in group 1 than in group $2(p<0.001)$.

Our results were consistent with Lyra et al., who reported improvement of IBS symptoms in patients prescribed by low dose L. acidophilus $\left(9.8 \times 10^{9} \mathrm{CFU} /\right.$ capsule) for 14 weeks, with a mean IBS-SSS sum score reduction from baseline corresponding to $-44.0 \pm 80.2$ [21].

In addition, Ishaque et al. found that the probiotic treatment significantly improved IBS symptoms and QOL in the intervention group compared to the placebo group [22].

In the current study, regarding the changes in the QOL at the baseline and after 4 weeks of treatment in group 1, there was highly significant improvement in all the terms of the QOL before and after treatment. On the other hand, QOL scores for group 2 at the baseline and after 4 weeks of treatment showed improvement of some terms of QOL such as dysphoria, interference with activity, body image, and health worry, while all other terms were not improved. The overall QOL score in group 2 showed no significant change after 4 weeks of treatment.

The current study also showed that there was a highly significant difference between the 2 groups regarding the overall QOL so we found that the mean score for group 1 was $91.54 \pm 7.78$ while that for group 2 was $69.71 \pm 7.23$, indicating significant change in score over time between the 2 groups $(P<0.001)$.

These results are consistent with study by Drossman et al., who concluded that the IBS-QOL is responsive to treatment in a referral-based clinical population of patients with IBS [23]. In agreement with our results, 
Williams et al. reported that probiotics improved the QOL from baseline rather than placebo [24]. Michail et al. showed a significant positive effect on the overall average QOL score in both probiotics and placebo groups after 8 weeks of treatment [25].

On the other hand, Ki Cha et al. reported that the changes of QOL from baseline in the follow-up period were statistically similar in probiotics- and placeboreceiving patients [26].

To our knowledge, this is the first study in North Africa and the Middle East to use the irritable bowel syndrome-symptom severity scale (IBS-SSS) (Arabic version licensed by Rome Foundation).

\section{Conclusion}

Our data suggest that probiotics are useful for the improvement of symptoms and quality of life of the IBS patients and could significantly improve the overall symptom response in IBS patients compared with placebo.

\section{The limitations of the current study}

The limitations of the current study are the relatively small number of the studied patients and the limited duration of follow up. Additionally, we need more comparative studies between different types of probiotics.

\section{Abbreviations}

IBS: Irritable bowel syndrome; IBS-SSS: Irritable bowel syndrome-symptom severity scale; IBS-QOL: Irritable bowel syndrome-quality of life

\section{Acknowledgements}

Rome Foundation for providing us with the Arabic version of the IBS-SSS and IBS-QOL for research and scientific purposes.

\section{Authors' contributions}

EF shared in the manuscript writing and revision of the data for all of the patients. EG revised of the final manuscript. OA collected the patients' data and followed them up. HA put the frame of the idea and wrote the manuscript. The authors read and approved the final manuscript.

\section{Funding}

This study was funded by the authors.

\section{Availability of data and materials}

The authors confirm that the data supporting the finding of this study are available within the article.

\section{Declarations}

Ethics approval and consent to participate

This study was conducted between Tropical Medicine Department, Ain Shams University and Egypt Air Hospital after obtained approval of Ethics Committee of Ain Shams University [FMASU REC] prospectively (MS/250/ 2019) in 28 August 2019, in accordance with local research governance requirements, the trial was also registered retrospectively with the federal clearinghouse for randomized trials on the ClinicalTrials.gov (NCT04572932) in October 2020 [https://clinicaltrials.gov/ct2/show/NCT04572932]. Written consent was taken from each patient who agreed to participate in the research process.

\section{Consent for publication}

Informed consent to publish patients' data was signed by all participants prior to the beginning of the research.

\section{Competing interests}

The authors declare that they have no competing interests, neither financial nor non-financial.

\section{Author details}

${ }^{1}$ Tropical Medicine Department, Ain Shams University Hospitals, Cairo, Egypt.

${ }^{2}$ General Medicine Department, Egypt Air Hospital, Cairo, Egypt.

Received: 12 March 2021 Accepted: 6 May 2021

Published online: 01 July 2021

References

1. Ford AC, Moayyedi P, Lacy BE et al (2014) American College of Gastroenterology monograph on the management of irritable bowel syndrome and chronic idiopathic constipation. Am J Gastroenterol 109:2-26

2. Drossman DA (2016) Functional gastrointestinal disorders: history, pathophysiology, clinical features, and ROME IV. Gastroenterol 150(6):12621279. https://doi.org/10.1053/j.gastro.2016.02.032

3. Simren M, Palsson OS, Whitehead WE et al (2017) Update on ROME IV criteria for colorectal disorders: implication for clinical practice. Curr Gastroenterol Rep 19(4):15

4. Klem F, Wadhwa A, Prokop LJ, Sundt WJ, Farrugia G, Camilleri M, Singh S, Grover M (2017) Prevalence, risk factors, and outcomes of irritable bowel syndrome after infectious enteritis: a systematic review and meta-analysis. Gastroenterol 152(5):1042-1054. https://doi.org/10.1053/j.gastro.2016.12.039

5. Moraes-Filho JP, Quigley EM (2015) The intestinal microbiota and the role of probiotics in irritable bowel syndrome: a review. Arq Gastroenterol 52(4): 331-338. https://doi.org/10.1590/S0004-28032015000400015

6. Johnsen PH, Hilpüsch F, Cavanagh JP, Leikanger IS, Kolstad C, Valle PC, Goll $R$ (2017) Faecal microbiota transplantation versus placebo for moderate-tosevere irritable bowel syndrome: a double-blind, randomised, placebocontrolled, parallel-group, single-centre trial. Lancet Gastroenterol Hepatol 3(1):17-24. https://doi.org/10.1016/\$2468-1253(17)30338-2

7. Zhuang X, Xiong L, Li L, Li M, Chen M (2017) Alterations of gut microbiota in patients with irritable bowel syndrome: a systematic review and meta-analysis. J Gastroenterol Hepatol 32(1):28-38. https://doi.org/10.1111/jgh.13471

8. Pedron T, Sansonetti P (2008) Commensals, bacterial pathogens and intestinal inflammation: an intriguing menage a trois. Cell Host Microbe 3(6) 344-347. https://doi.org/10.1016/j.chom.2008.05.010

9. Carroll IM, Ringel-Kulka T, Siddle JP, Ringel Y (2012) Alterations in composition and diversity of the intestinal microbiota in patients with diarrhea predominant irritable bowel syndrome. Neurogastroenterol Motil 24(6):521-530. https://doi.org/10.1111/j.1365-2982.2012.01891.x

10. Drossman DA, Hasler WL (2016) Rome IV_functional GI disorders: disorders of gut-brain interaction. Gastroenterol 150(6):1257-1261. https://doi.org/1 0.1053/j.gastro.2016.03.035

11. Dai $C$, Zheng $C Q$, Jiang $M, M a X Y$, Jiang $\sqcup$ (2013) Probiotics and irritable bowel syndrome. World J Gastroenterol 19(36):5973-5980. https://doi.org/1 0.3748/wjg.v19.i36.5973

12. Didari $T$ (2015) Effectiveness of probiotics in irritable bowel syndrome: updated systematic review with meta-analysis. World J Gastroenterol 21(10): 3072-3084. https://doi.org/10.3748/wjg.v21.i10.3072

13. Lovell RM, Ford AC (2012) Global prevalence of and risk factors for irritable bowel syndrome: a meta-analysis. Clin Gastroenterol Hepatol 10:712-721

14. Jafari E, Vahedi H, Merat S, Momtahen S, Riahi A (2014) Therapeutic effects, tolerability and safety of a multi-strain probiotic in Iranian adults with irritable bowel syndrome and bloating. Arch Iran Med 17:466-470

15. Ludidi S, Jonkers DM, Koning CJ, Kruimel JW, Mulder L, van der Vaart IB, Conchillo JM, Masclee AAM (2014) Randomized clinical trial on the effect of a multispecies probiotic on visceroperception in hypersensitive IBS patients. Neurogastroenterol Motil 26(5):705-714. https://doi.org/10.1111/nmo.12320

16. Lee OY (2010) Asian motility studies in irritable bowel syndrome. J Neurogastroenterol Motil 16(2):120-130. https://doi.org/10.5056/jnm.2010.1 6.2 .120

17. Ghoshal UC, Singh R (2017) Frequency and risk factors of functional gastrointestinal disorders in a rural Indian population. J Gastroenterol Hepatol 32(2):378-387. https://doi.org/10.1111/jgh.13465 
18. Rahman MM, Mahadeva S, Ghoshal UC (2017) Epidemiological and clinical perspectives on irritable bowel syndrome in India, Bangladesh and Malaysia: a review. World J Gastroenterol 23(37):6788-6801. https://doi.org/10.3748/ wjg.v23.i37.6788

19. Palsson OS, Whitehead WE (2013) Psychological treatments in functional gastrointestinal disorders: a primer for the gastroenterologist. ClinGastroenterolHepatol 11:208-216

20. Rome Foundation official Website: https://therome-foundation.org/ questionnaires/. Accessed May 2019.

21. Lyra A, Hillila M, Huttunen T et al (2016) Irritable bowel syndrome symptom severity improves equally with probiotic and placebo. World J Gastroenterol 22(48):10631-10642. https://doi.org/10.3748/wjg.v22.i48.10631

22. Ishaque SM, Khosruzzaman SM, Ahmed DS, Sah MP (2018) A randomized placebo-controlled clinical trial of a multi-strain probiotic formulation (BioKult(R)) in the management of diarrhea-predominant irritable bowel syndrome. BMC Gastroenterol 18(1):71. https://doi.org/10.1186/s12876-0180788-9

23. Drossman DA, Patrick DL, Whitehead WE (2000) Further validation of the IBS-QOL: a disease specific quality of life questionnaire. Am J Gastroenterol 95(4):999-1007. https://doi.org/10.1111/j.1572-0241.2000.01941.x

24. Williams EA, Stimpson J, Wang D et al (2009) Clinical trial: a multistrain probiotic preparation significantly reduces symptoms of irritable bowel syndrome in a double-blind placebo-controlled study. Aliment Pharmacol Ther 29:7-103

25. Michail S, Kenche H (2011) Gut microbiota is not modified by randomized, double-blind, placebo-controlled trial of VSL\#3 in diarrhea-predominant irritable bowel syndrome. Probiotics Antimicrob Proteins 3(1):1-7. https:// doi.org/10.1007/s12602-010-9059-y

26. Ki Cha B, Mun Jung S, Hwan Choi C, Song ID, Woong Lee H, Joon Kim H, Hyuk J, Kyung Chang S, Kim K, Chung WS, Seo JG (2012) The effect of a multispecies probiotic mixture on the symptoms and fecal microbiota in diarrhea-dominant irritable bowel syndrome: a randomized, double-blind, placebo-controlled trial. J Clin Gastroenterol 46(3):220-227. https://doi.org/1 0.1097/MCG.0b013e31823712b1

\section{Publisher's Note}

Springer Nature remains neutral with regard to jurisdictional claims in published maps and institutional affiliations.

\section{Submit your manuscript to a SpringerOpen ${ }^{\circ}$ journal and benefit from:}

- Convenient online submission

- Rigorous peer review

- Open access: articles freely available online

- High visibility within the field

- Retaining the copyright to your article

Submit your next manuscript at $\boldsymbol{\nabla}$ springeropen.com 